\title{
Building trust in SWAT model scenarios through a multi- institutional approach in Uruguay
}

\author{
Flora Mer ${ }^{1,2^{*}}$, Walter Baethgen ${ }^{2}$, R. Willem Vervoort ${ }^{3}$ \\ ${ }^{1}$ Instituto Nacional de Investigación Agropecuaria, Uruguay \\ ${ }^{2}$ International Research Institute for Climate and Society, The Earth Institute, Columbia University, New York, \\ USA \\ ${ }^{3}$ Sydney Institute of Agriculture, School of Life and Environmental Sciences, The University of Sydney, NSW, \\ Australia
}

\begin{abstract}
The inherent complexity of numerical models and the diversity of stakeholders in integrated water resources management (IWRM) create challenges in achieving credibility, salience and legitimacy to develop trust in modelbased scenarios. In Uruguay, there has been significant debate on increasing agricultural production while managing agriculture's environmental impacts (e.g., on water quality and environmental flows). This paper reports on the evolution of a stakeholder process in a case study with a multi-institutional participatory modelling group, supported by researchers. This specific participatory modelling (PM) project is unique in that the active stakeholders are the actual hydrological modellers, and the role of "experts" is mainly in facilitation and capacity building. The results highlight the different bottlenecks and the factors that enabled effective collaboration in this PM project. The main bottlenecks were related to: different views on representation of the watershed, the quality and usability of different input data, the public information for the technical implementation of the model, and the priority of output scenarios. The factors that enhanced collaboration were: a focus on a single basin problem, strong support from upper management, and support from experts in coordination and capacity building. The detailed documentation provided with this project can inspire similar approaches in the future.
\end{abstract}

\section{Keywords}

Integrated Water Resource Management; hydrological modelling; stakeholder modelling; capacity building

\section{Introduction}

Developing policies to implement integrated water management and sustainable development at a landscape scale is an important challenge faced by planners, researchers and decision makers (Cosgrove and Loucks, 2015). As global demand for food, driven by population growth and dietary changes, is predicted to double in the next 50 years (Molden, 2013), there is increasing pressure on water and land (de Fraiture and Wichelns, 2010) and key questions around sustainable management of water and land need to be answered (Cosgrove and Loucks, 2015). Integrated water resource management (IWRM) approaches have been promoted as a solution to overcoming conflicts in water management and as an effective way to engage stakeholders in the planning process (Badham et al., 2019). However, an on-going complaint about IWRM is that, despite the extensive analysis and development of multiple frameworks (e.g. Hamilton et al., 2015), there is still a limited number of good case studies on the actual implementation of IWRM (Badham et al., 2019).

Correspondence:

Contact F. Mer at merfloraa@gmail.com

Cite this article as:

Mer, F., Baethgen, W., \& Vervoort, R.W.

Building trust in SWAT model scenarios through a multi-institutional approach in Uruguay

Socio-Environmental Systems Modelling, vol. 2, 17892, 2020, doi:10.18174/sesmo.2020a17892

This work is licensed under a Creative Commons Attribution-NonCommercial 4.0 International License. 
Modelling tools are essential for IWRM as models summarise the available data and knowledge, and can be used for subsequent scenario analyses that can be tested. As a result, models are seen as effective tools for communicating with stakeholders in an IWRM process using participatory modelling (PM) (Basco-Carrera et al., 2017; Falconi and Palmer, 2017). However, communication of model results often fails in practice (Basco-Carrera et al., 2017). Communication of results based on models can be challenging because models are not always intuitive tools for stakeholders that are not familiar with their use. There are two specific issues, the first is related to model choice. The choice of model is often driven by the modeller's experience and preference, rather than being chosen by the stakeholder group (Olsson and Andersson, 2007; Prell et al., 2007). As a result: "Models are laden with choices and thus depend on assumptions and priorities of modellers" (Olsson and Anderson, 2007, p. 99). In part, this is related to the modellers' loss aversion and confirmation risk biases (Hämäläinen, 2015).

A second issue is that models can be complex and are inherently uncertain due to the simplifications in their structure to represent "real basins" (Olsson and Andersson, 2007). Consequently, Haasnoot et al. (2014) have recently argued that the structure of models should be as simple as possible, given that potential pathways are all that can be identified. Modelling scenarios can be particularly problematic, because models can never be fully verified (Olsson and Andersson, 2007; Oreskes et al., 1994), and therefore, assumptions need to be defined in a way that ensures that scenarios are realistic and credible. This also requires that stakeholders are fully engaged in the modelling process and are able to make decisions on model development and scenario assumptions (Falconi and Palmer, 2017). However, in most cases stakeholders are only involved in checking model implementation and data inputs, in evaluating results, and/or in data collection (Voinov et al., 2016), mostly because the model and the process are not fully transparent and understandable for all participants (Langsdale et al., 2013).

Because of these difficulties in communication of the technical (model) approaches with a group of stakeholders with varying backgrounds, trust is the characteristic that leads most directly to success in IWRM. In particular, trust in the stakeholder group, the modellers and the process (Falconi and Palmer, 2017; Langsdale et al., 2013; Merritt et al., 2017). This might require high quality facilitation or facilitation skills from the model experts (Langsdale et al., 2013), but more importantly the model and model outputs and outcomes need to be credible, salient and legitimate (Cash et al., 2003; Falconi and Palmer, 2017). Here we interpret model outputs as the actual results of model runs and scenario runs, while model outcomes are how those outputs are translated into policy advice.

Credibility is defined by Falconi and Palmer (2017) as related to the quality of the information that the model produces; does the model accurately represent the system as seen by the stakeholders? Salience relates to the specific topic of the modelling: is this a problem that the stakeholders would like to see addressed? But it can also relate to the modelling itself (Falconi and Palmer, 2017): do the model outcomes address the needs of the stakeholders? Finally, legitimacy means the model is seen as unbiased and does not represent a specific view point.

Papers which outline recommendations or best practice in modelling with stakeholders often discuss detailed requirements in terms of the planning process, stakeholder selection and model development (i.e. Langsdale et al., 2013). However, in many cases ad-hoc groups created as a result of an opportunity to engage in a project, work on IWRM processes without careful planning. Had more careful planning taken place, the IWRM process could have been more successful (Merritt et al., 2017). As a result, continuing to document experiences with IWRM will allow other groups to learn from previous experiences (Badham et al., 2019).

Even though Badham et al. (2019) highlight that more case studies are needed, there are already many reported case studies focused on stakeholder consultation and PM (for example as reviewed by Falconi and Palmer, 2017; Merritt et al., 2017). From the literature, it seems that most existing case studies focus on a collaboration between modellers (the experts), and stakeholders from government organisations and/or local communities. This case study reports on a PM approach (Voinov et al. 2016), which combines collaborative learning about modelling with policy development, involving stakeholders from different institutions in Uruguay. The main difference with earlier studies is in the definition of the "stakeholder". 
In our study, we define stakeholders as anyone with an interest (stake) in an integrated water management project. These stakeholders can be further subdivided into:

- Active (core) stakeholders: those who participate in the meetings, including those more active in meetings and more "hands-on" using the model to develop scenarios or analyses for the project ("core modellers"), and those who are not "hands-on" with the model but provide the main internal feedback ("controllers");

- External or decision-maker stakeholders: stakeholders external to the core group working with the model results, that are part of the participating institutions. They provide external feedback and often make decisions on the funding and time allocation of the active stakeholders; and

- General interested public and indirect stakeholders who might come to information meetings. They may be interested in staying informed about the results of the project.

- Experts: experts in the domain area who assist the active stakeholders with actual modelling and interpreting results.

In our case, the facilitator role is taken by one of the experts.

There are limited examples of studies, where the active stakeholders choose the model and aim to become the model experts in the process (Voinov et al., 2016). In such cases, the active stakeholders need to develop trust and confidence in their own modelling skills, and/or in the modelling skills of their colleagues within the large stakeholder group, and as a group jointly develop model understanding to maintain legitimacy. In addition, they will need to be able to communicate the model results, uncertainty and policy implications to a wider group of participants, which we call "external stakeholders", including their supervisors.

Based on the above definitions and review, the aim of this paper is to discuss a case study from an IWRM pilot project in Uruguay to highlight the importance of building and maintaining trust, not only between stakeholders, but also trust in the overall modelling process. In addition, the case study is unique within the PM context because it involved active stakeholders becoming model experts in a multi-institution group. The paper focuses on the modelling case study as a narrative to highlight the different outcomes in relation to the different PM dimensions (Voinov et al., 2016). This article first discusses the context and background of the case study in Section 2.1, after which the general tools and approaches for the case study and the relationship to credibility, salience and legitimacy (as important requirements for trust) are discussed in Section $2.2-2.6$. This is followed by a description of the results of the case study, focusing on the stakeholder process in relation to trust. Technical details are highlighted when they are relevant to demonstrate participatory modelling processes (Section 3). A discussion in Section 4 analyses the results in the context of the existing PM literature, and draws out major issues and limitations, as well as opportunities for future research. Finally, in Section 5 we offer conclusions.

\section{Background and approach}

\subsection{Background, establishing salience and legitimacy}

In Uruguay, agriculture is one of the most important industries: more than $80 \%$ of its territory is agricultural land, and the sector contributes to more than $70 \%$ of export earnings (Oficina de Estadísticas Agropecuarias DIEA, 2017). Because agricultural activities dominate the landscape and agricultural production is of great economic importance, intensification of agriculture poses a distinct environmental risk at the landscape level, which influences the public opinion of agriculture. Therefore, identifying ways to develop a sustainable pathway to intensification of agricultural production is important for Uruguay.

The start of this project was a scoping workshop in June 2015, organised by the International Research Institute for Climate Society (IRI) and the National Agricultural Research Institute (INIA), which brought together the main stakeholders in water management in Uruguay: the Ministry of Livestock, Agriculture and Fisheries (MGAP); the National Environmental Directorate Agency of the Ministry of Housing, Spatial Planning and Environment (MVOTMA-DINAMA); the National Water Directorate agency of the Ministry of Housing, Spatial Planning and Environment (MVOTMA-DINAGUA); and relevant research institutions, such as the Department of Fluid Mechanics and Environmental Engineering (IMFIA) and the Department of Science, both of the Republic University (UdelaR). The stakeholders in this scoping workshop identified a clear need for capacity building in 
water management and land use planning at the basin level, based on models that can inform decision making. More specifically, there was a need to develop capacities to calibrate, evaluate and use hydrological models to support decision and policy making.

An outcome of this scoping workshop was that the main stakeholders supported the development of a multiinstitutional working group composed of active stakeholders to develop a modelling pilot project. This working group consisted of technical experts, mostly hydrological or agricultural engineers, from 5 different institutions, which ensured that the project would be relevant to the Uruguayan policy environment (Table 1). The aim of the pilot project was to explore and develop trustworthy (credible), jointly agreed (legitimate) and basin-scale modelling to be able to test scenarios to support policy development (Falconi and Palmer, 2017).

Table 1: Uruguayan government and research institutions, their main interest and number of participants in the stakeholder group of the project

\begin{tabular}{|c|c|c|c|}
\hline & Institutions & Main interest & $\begin{array}{l}\text { Participants in } \\
\text { the project }\end{array}$ \\
\hline \multirow{3}{*}{$\begin{array}{l}\text { Public } \\
\text { institutions }\end{array}$} & $\begin{array}{l}\text { The Ministry of Livestock, Agriculture and } \\
\text { Fisheries (MGAP) }\end{array}$ & $\begin{array}{l}\text { Define policy on sustainable } \\
\text { agricultural intensification. }\end{array}$ & $1-2^{*}$ \\
\hline & $\begin{array}{l}\text { The National Environmental Directorate } \\
\text { Agency of the Ministry of Housing, Spatial } \\
\text { Planning and Environment (MVOTMA- } \\
\text { DINAMA) }\end{array}$ & $\begin{array}{l}\text { Define policy on maintaining } \\
\text { environment quality }\end{array}$ & $3-4$ \\
\hline & $\begin{array}{l}\text { The National Water Directorate agency of the } \\
\text { Ministry of Housing, Spatial Planning and } \\
\text { Environment (MVOTMA-DINAGUA) }\end{array}$ & $\begin{array}{l}\text { Define policy on water use } \\
\text { (quantity) }\end{array}$ & 3 \\
\hline \multirow{2}{*}{$\begin{array}{l}\text { Research } \\
\text { centers and } \\
\text { universities }\end{array}$} & $\begin{array}{l}\text { The National Agricultural Research Institute } \\
\text { (INIA) }\end{array}$ & $\begin{array}{l}\text { Research for the sustainable } \\
\text { development of agriculture to } \\
\text { support public policy and the } \\
\text { private sector }\end{array}$ & 1 \\
\hline & $\begin{array}{l}\text { The Department of Fluid Mechanics and } \\
\text { Environmental Engineering (IMFIA) and the } \\
\text { Department of Science, both of the Republic } \\
\text { University (UdelaR) }\end{array}$ & $\begin{array}{l}\text { Educational institution: course } \\
\text { work and research in hydrology }\end{array}$ & 1 \\
\hline
\end{tabular}

* Participation varied over the period of the project

Some of the active stakeholders had modelling experience, but there was limited experience with spatial hydrological modelling in general. External expertise for the hydrological modelling was provided by experts, who are the co-authors of this paper, from the International Research Institute for Climate and Society (IRI, Columbia University) and the University of Sydney (USYD) through the "INIA-IRI-USYD project" (Project FPTA 341: INIA). The overall aim of this project was to develop tools and capacity to improve management of climaterelated risks in the agricultural sector in the Southern Cone region of South America.

Given that Uruguay is a relatively small country with well-organised institutions, it offered a good opportunity to bring together all the main players in water management to provide a model for similar integrated water management efforts in other countries.

\subsection{Establishment and functioning of the active stakeholder working group}

The approach used in this participatory modelling (PM) project (Voinov et al., 2016) follows aspects of the collaborative governance model described by Ansell and Gash (2008) and the requirements described by Falconi and Palmer (2017). An important step in creating legitimacy and credibility for the active stakeholder group was a result of the earlier mentioned scoping workshop in June 2015 (Table 2). This workshop allowed the leadership in different government departments to highlight knowledge gaps which needed to be addressed to enable the use of models to support decision making. The formation and support of the active stakeholder group 
subsequently aimed to address identified knowledge gaps in model implementation and identify data for scenario development. To strengthen credibility, existing initiatives involving hydrological modeling were first reviewed to understand the existing "hydrological modelling landscape" in Uruguay and not duplicate efforts.

Because decision makers from different government institutions participated in the project development process, legitimacy was established. Moreover, management in the government departments identified the staff which could participate as active stakeholders. Existing cooperation between institutions in Uruguay helped with building trust in the process. Importantly, active stakeholders involved in the project had no negative prehistory (Ansell and Gash, 2007).

The next step was the development of an official draft proposal by the active stakeholder group in face-to-face meetings, until all agreed with the objective and activities planned for the pilot project. A subbasin of the Santa Lucia river was identified as a focus area. The main stakeholders within the government departments proposed SWAT (Arnold et al., 2012) as the preferred modelling tool to deliver spatially detailed outputs, and this was further discussed during the active stakeholder meetings. While one department had prior experience with a different tool (AQUATool) they were not completely satisfied with this model and were keen to try something different. The rest of the stakeholders had little to no experience with models. As a result, the active stakeholders agreed to use the SWAT model as the preferred modelling tool. The proposal document was also an important step for the active stakeholders to have their time commitment approved by management in the institutions. The proposal formalised the institutional collaboration, and officially created the multi-institutional active stakeholder group. This meant that all active stakeholders were committed to the PM process defined in the proposal, as their supervisors sanctioned their time on the project. It also meant that the management in the participating institutions were interested in the progress of the active stakeholder group and therefore, were interested in the PM outcomes.

Once the pilot project proposal was approved by all stakeholders, a member of the IRI team took on the role as the "coordinator" or facilitator. Initially the membership of the active stakeholder group fluctuated. Once the active stakeholder group met more regularly, the membership stabilised, although it continued to vary depending on the interest and time commitment of individual members. The coordinator structured each weekly meeting by circulating an agenda and a summary of the progress. During the meeting, tasks were discussed, decided and assigned to group members on a voluntary basis. The role of the coordinator was to document the process, maintain a clear overview of the group rules, achievements and objectives and to facilitate dialogue.

As highlighted, MVOTMA-DINAMA earlier initiated work with a simpler model called AQUATool at a fairly coarse basin scale to provide a preliminary validation of proposed management practices. However, as a result of the experience and external inputs (including a report by a World Bank consultant) and advice, they were interested to move to a more complex model such as SWAT.

The active stakeholder group, naturally, had different levels of enthusiasm for both the modelling and SWAT as a modelling tool. To support the active stakeholder group, and build trust in the approach a series of capacity building events were organised (Table 2). First a series of basic capacity building workshops (Table 2) was organised to allow familiarization with the SWAT model and the associated optimization tool SWAT-CUP (Abbaspour et al. 2015). This gave insight into the model strengths and limitations, and the need to include local data (see section 2.5). To further support the modelling experience and to continue trust building the active stakeholders worked together on model building in weekly meetings coordinated by the IRI team. This was combined with domain expert advice from USYD and from other "trusted" domain specialists in Argentina through in-person and video link meetings. The additional technical expertise from other Latin American groups was suggested by active stakeholders in the group. Finally, further advice was sought from the developers of the SWAT model for specific information.

After a few meetings, the active stakeholder group organically developed two types of participants: the "core modellers", which were stakeholders willing to actually run the SWAT model; and the "controllers", which were stakeholders who would check the model output in relation to their experience, and would be consulted in relation to model inputs. "Core modellers" and "controllers" are similar to "modellers" and "gatekeepers" which are among the five essential stakeholder roles defined in Renger et al. (2008). The three other essential roles are facilitator, process coach and recorder and are all integrated under the expert role in our study. Overall, this 
Table 2: Outline of the different steps in the process and timeline of the process

\begin{tabular}{|c|c|c|}
\hline Timeline & Activity purpose & Outcomes \\
\hline \multirow[t]{2}{*}{ June 2015} & \multirow{2}{*}{$\begin{array}{l}\text { Scoping workshop to define } \\
\text { research needs in water } \\
\text { resources }\end{array}$} & One common demand of all institutions managing water: \\
\hline & & $\begin{array}{l}\text { Needs to develop capacity building in Uruguay to use model to } \\
\text { support water management at basin scale. }\end{array}$ \\
\hline $\begin{array}{l}\text { June } 2015 \text { to } \\
\text { December } 2016\end{array}$ & Model selection & $\begin{array}{l}\text { The SWAT model is a good candidate to use in Uruguay: } \\
\text { scenario analysis, used internationally, big community of users. }\end{array}$ \\
\hline \multirow[t]{3}{*}{$\begin{array}{l}\text { May \& August } \\
2017\end{array}$} & \multirow[t]{3}{*}{ Model capacity building } & $\begin{array}{l}\text { Several persons from different institutions participated to } 2 \\
\text { capacity buildings workshops: }\end{array}$ \\
\hline & & - Introduction to SWAT workshop \\
\hline & & - SWATCUP optimization and the use of satellite data workshop \\
\hline October 2017 & $\begin{array}{l}\text { Inter-institutional active } \\
\text { stakeholder group } \\
\text { establishment }\end{array}$ & $\begin{array}{l}\text { Merging all individual initiative together and formation of the } \\
\text { inter-institutional working group on using SWAT as a tool to } \\
\text { support water management policies }\end{array}$ \\
\hline \multirow[t]{8}{*}{ January 2018} & \multirow{8}{*}{$\begin{array}{l}\text { Start of Pilot project } \\
\text { To continue exploring the SWAT } \\
\text { model }\end{array}$} & With the group, definition of the pilot project and activities to \\
\hline & & complete: \\
\hline & & $\begin{array}{l}\text { The objective is to "Estimate the impact of land uses on the } \\
\text { quantity and quality of the water resource in the sub-basin of } \\
\text { the Santa Lucia River to the Santa Lucia Chico River using the } \\
\text { SWAT model" }\end{array}$ \\
\hline & & The activities defined are: \\
\hline & & 1- Implement the SWAT model with the existing input information. \\
\hline & & $\begin{array}{l}\text { 2- Calibrate the SWAT model with SWATCUP and obtain the best } \\
\text { possible fit with the currently available data. }\end{array}$ \\
\hline & & $\begin{array}{l}\text { 3- Validate the SWAT model with SWATCUP and quantify } \\
\text { uncertainty }\end{array}$ \\
\hline & & $\begin{array}{l}\text { 4- Estimate the impacts of land use on the quantity and quality of } \\
\text { water, to support the planning of land use planning by running } \\
\text { scenarios }\end{array}$ \\
\hline February 2019 & $\begin{array}{l}\text { Pilot project scenario definition } \\
\text { workshop }\end{array}$ & $\begin{array}{l}\text { Workshop to present progress and ask help to heads of } \\
\text { department (external stakeholders) to define interested scenario } \\
\text { which would be studied within the pilot project. }\end{array}$ \\
\hline \multirow[t]{2}{*}{ June 2019} & \multirow{2}{*}{$\begin{array}{l}\text { Result presentation of Pilot } \\
\text { project }\end{array}$} & Workshop to present some results of the pilot project \\
\hline & & $\begin{array}{l}\text { Continue to run specific scenario analysis for the Santa Lucia } \\
\text { subbasin }\end{array}$ \\
\hline March 2020 & End of Pilot project & $\begin{array}{l}\text { Next steps: continue the working group and extend the use of } \\
\text { SWAT for other basin }\end{array}$ \\
\hline
\end{tabular}

meant that the project included several layers of influence (Figure 1), which matches the description of the roles of stakeholders in Voinov and Bousquet (2010) and Renger et al. (2008).

This arrangement (Figure 1) provided transparency for the different stakeholder groups, in terms of the different steps in the process and the outcomes of the project. This transparency of the process was strengthened through several workshops (Table 2), where the overall progress and decision points of the project were presented by the active stakeholders to managers and other stakeholders. The workshops also created an opportunity to ask for input from managerial stakeholders who are decision makers (external stakeholders) and the wider Uruguayan research community, the indirect stakeholders. 


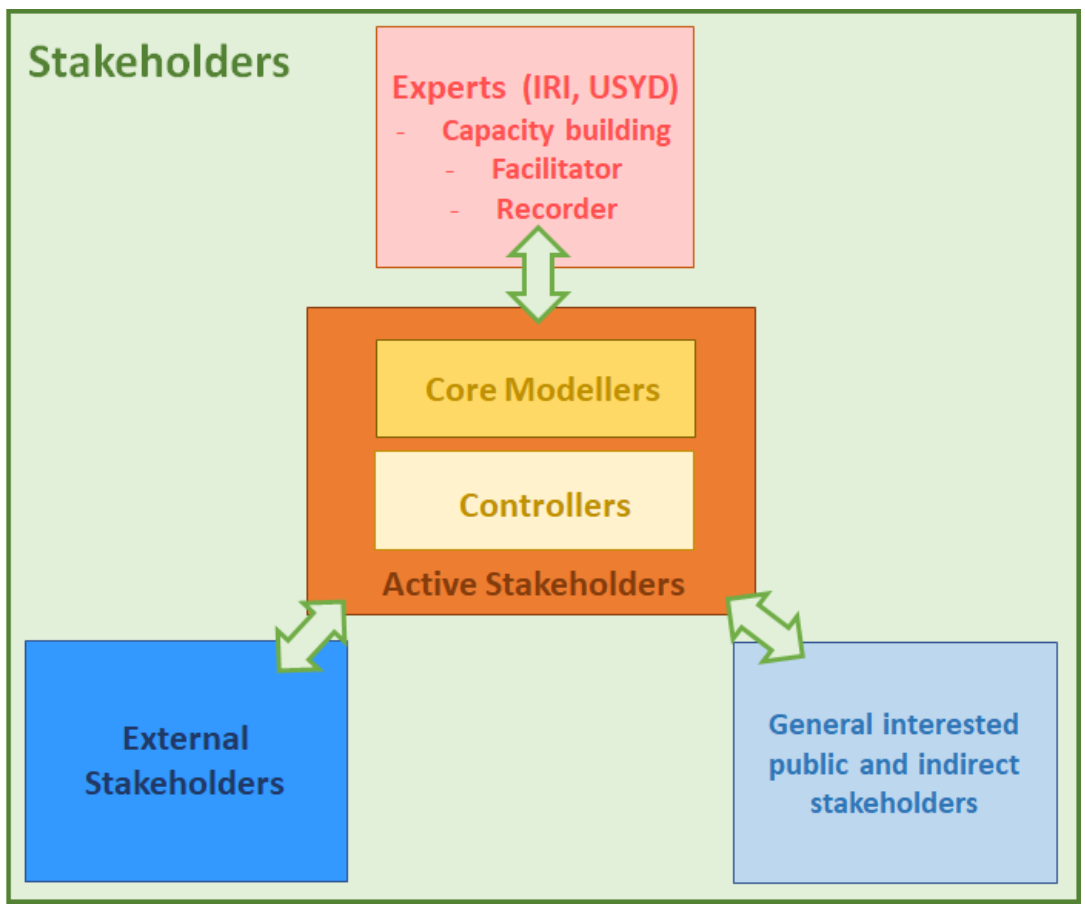

Figure 1: Layers of influence for the project (after Langsdale et al., 2013).

\subsection{Description of the study site: the saliency of the project}

The project concentrated on the Santa Lucia basin as a case study. This basin is the main source of drinking water for the capital city of Uruguay, Montevideo. It delivers water to 1.6 million people (about $60 \%$ of the country's population) and also supports several agro-industrial activities (Achkar et al., 2012). In consultation with the main stakeholder group (line managers and active stakeholders), the work focused on the basin above Paso Pache $\left(4,896 \mathrm{~km}^{2}\right)$. This choice was strengthened by the existence of a hydrometeorological network with 28 rain gauges, 5 fairly complete stream gauge datasets and 1 meteorological station (Figure S1), which the stakeholder group considered to provide sufficient input data.

The basin generally consists of a rolling landscape with low hills and plains. The soils are generally shallow with low water storing capacity. In 2015 the main land use was grassland (54\%), followed by small grains and row crop agriculture (34\%) and forestry (Eucalyptus, 9\%). One of the main concerns for the stakeholders is that the forestry and crop production sectors have changed considerably over the last 30 years. More specifically, the area of forest cover has increased substantially and the local water authority (DINAGUA, Dirección Nacional de Aguas) has increasingly provided water allocations, mainly for irrigation, livestock and domestic use, which is suggested to have changed streamflows (Navas et al., 2019). Moreover, there is evidence that the amount of nitrogen and phosphorus applied to the agricultural fields has increased considerably and this might also impact the surface water quality (Barreto et al., 2017).

Overall this has created increased stakeholder concerns about water quality in the basin. For example, in 2013, a harmful algal bloom in the Santa Lucia basin caused bad taste and odor in the drinking-water of Montevideo. This event triggered an "Action Plan" for the Santa Lucia basin developed by the government, which included best management practices to be implemented (Barreto et al., 2017). To validate the suggested practices, several government departments initiated development of different management models at the basin scale.

\subsection{Model implementation}

\section{Model description and watershed delineation}

A key element in scenario analyses is the choice of model. The model has to be credible and legitimate to the stakeholders. The SWAT model is a widely used, semi-distributed hydrologic model which mixes detailed physical descriptions with conceptual hydrological elements. It is potentially capable of simulating spatial effects 
of water quantity and water quality processes in a watershed, based on detailed information on agricultural management practices (Arnold et al., 2012).

Detailing part of the implementation of the SWAT model is relevant as this involves three main steps and decision points that can influence the outcomes. These steps are: 1) delineation of the watershed into sub basins, 2) creation of hydrological response units (HRUs) based on combinations of land use, slope and soil types, and 3 ) input of management data, climate data and time periods for the simulation and execution of the SWAT model.

The basic unit of all model calculations in SWAT is the HRU. HRUs are defined for each subbasin as aggregations of unique combinations of land use, soil and slope classes. This means that all pixels in a subbasin with the same combination of land use, soil type and slope class are combined to form one unit for calculation. HRU responses are then accumulated into a subbasin water balance, and the flow and associated water quality constituents from a subbasin are routed through the stream network to the overall basin outlet. A minimum threshold for soil area, land use area and slope class can be defined to reduce the number of very small units, but this impacts the model results. At the HRU creation step (and subsequent steps) the same criteria were used by all the group members to define these thresholds. Elevations were grouped into two main classes, as the landscape is mostly flat, and in the definition of the HRUs a threshold was used that implied at least $10 \%$ of the area should be represented by a specific soil type, land use and slope class.

In SWAT, the stream network scale and the subbasin level determine the level of spatial detail that can be simulated with the model. As it will be further detailed in the project results section, the group decided to work at two different subbasin levels by creating two sub working groups: a coarser resolution "level 3" (MVOTMADINAMA, IMFIA and MGAP) and a finer resolution "level 5" (MVOTMA-DINAGUA). The "level" refers to the official basin division or resolution used by MVOTMA and MGAP.

\section{Identification of legitimate datasets for the model}

The underlying datasets that we used needed to be accepted at all levels of government ("a single source of truth"). As a result the active stakeholder group focused only on published government datasets rather than developing their own datasets (for example a land use classification, Supplementary Material Table S1). The active stakeholder group went through quality checks for each dataset and consulted with external experts to find a consensus on the best available data. The external experts were mainly personal or professional contacts of the active stakeholders group members. There was no specific selection process to identify "an expert". In this section we highlight some of the data chosen for the model implementation.

Among the several land use maps published, the active stakeholder group decided to discard some of the land use maps due to poor quality and keep the 2000 and 2015 land use map available. The model was first developed using the 2000 land use map considering stationarity of the land use period for improved flow calibration. However, after some discussion about the available water quality data, the group moved to the 2015 land use map implementation to enable combined water quantity and quality calibration.

Within SWAT, fairly detailed crop rotations can be simulated, including management such as fertilizer applications, tillage and crop choices. Several weekly meetings were dedicated to the definition of crop rotations and implementation in the model. Finally, three main rotations were defined, which are detailed in Table S2 of the Supplementary Material. To include variability in relation to the starting year of a rotation, different crops were randomly assigned to "even" and "odd" subbasin numbers for a specific rotation.

The underlying soil data in the model was based on a 1:40,000 soil map and on data from local soil observations provided by MGAP. Finally, in order to include diffuse contamination from dairy farms, the active stakeholder group decided to include one point source per subbasin.

The model calibration and validation continued to progress, and data and model were continuously being updated as new information became available. While this slowed the overall progress, the active stakeholder group considered it important to use the "best available data". In addition, in collaboration with the wider stakeholders, the active stakeholder group defined several scenarios to test with the model. 


\subsection{Documentation and data storage}

Documenting the outcomes and decisions for each development step, and creating a shared storage for all data, results and models was an important component of the project, because it maintains legitimacy as a "single source of truth". Initially a Google Drive folder, managed by the group coordinator, was used to store the latest model runs, latest model versions and all input and output data. While access was open to the active stakeholders, the general organisation and structure was managed by the group coordinator. This folder also contained capacity building examples and support documentation to develop the modelling skills in the group.

At a later stage, a majority of support documents and tutorials focusing on methodology, analyses and decisions in relation to the modelling were moved to an Open Science Framework (OSF) project: https://osf.io/uqb5j/, which is public.

\section{Project results}

\subsection{Main results and processes}

\section{Multi-institutional work \& collaboration results}

The main result was an active stakeholder participatory modelling (PM) group (modellers and controllers) that cooperated effectively, producing jointly agreed, credible model results (such as simulated streamflow at different monitoring stations, predictions of water quality, crop yield, etc). Our measure of success was the stability of the core group membership, as well as the continued attendance of supervisors at the larger stakeholder workshops, including experts, line managers and department heads. While this might seem an obvious outcome, this is not necessarily the case.

Despite the different missions and objectives of the stakeholder institutions (Table 1), the project functioned well as it: (a) focused on a single modelling tool, and (b) focused on problems and challenges that were relevant (salient) for all institutions. For example, within the model implementation and scenario development, stakeholders from MGAP could focus on intensification of agricultural production (e.g., introducing irrigation), while stakeholders of DINAMA could focus on environmental conservation and water quality, and DINAGUA stakeholders mainly focused on water quantity for bulk water supply (Table 1).

The lack of negative history of the participants worked as a catalyst for open collaboration (Ansell and Gash, 2007). This was strengthened by the active support for collaboration from the supervisors in the respective departments, creating an important boundary condition. The support from the supervisors also kept the project focusing on issues that were relevant to all the stakeholder institutions. This in turn, gave salience to the generated knowledge. As a result, the group collaboratively worked through several challenging discussions related to key decision points in the modelling process. Some examples of these are described in more detail in the subsection "Model implementation results". Generally, those challenging discussions were resolved based on literature research by group members and bringing external experts to the table for advice.

This project also strengthened the interaction between different institutions, both within and beyond the active stakeholder working group. This was mainly the result of the regular larger workshops that included supervisors and which solicited their feedback.

\section{Capacity building results}

Another important result of the project was the increased capability in modelling within the active stakeholder group and increased general understanding of landscape modelling among the larger stakeholder group. The initial major workshops between May and August 2017 (Table 2) established a base level of confidence for the active stakeholders engaged in the modelling process. Individual confidence of the active stakeholders in the modelling process increased over time, which was important to establish credibility in the model outputs. The active stakeholder group transitioned from being mostly dependent on the experts from USYD and IRI team to becoming an independent modelling team in the weekly meetings. Initially there were many questions about basic processes in the model, and the USYD/IRI experts were heavily involved in implementing the model and building capacity around data selection, model set-up and calibration during the weekly meetings. At those first weekly meetings, the experts would present progress in the modeling work to the active stakeholder working 
group. This work was subsequently repeated by some of the participants over the week, but generally the participants focused on the data collection. However, the activities and support developed confidence in the active stakeholders for making decisions on model implementation and engaged them with the modelling process.

After one year of the project, "modellers" in the active stakeholder group brought their own modeling results to the weekly meeting, which were subsequently discussed. In addition, the active stakeholders developed initiatives to improve the original dataset and the overall model results. This was particularly obvious in the second part of the project, where at some point five different model realisations were running to compare results (explained below in "model implementation results"; this included two scenarios and two different spatial resolutions). The active stakeholder group collaboratively reviewed the results, identified problems and solutions and restarted simulations to bring all results to a consensus level.

A key focus in the capacity building effort was to work on "model process understanding". This meant developing a clear understanding on how the model represents the reality, what this means in terms of limitations of the model, and how this might impact the model results. Establishing consensus about the local landscape processes, between the modellers and controllers in the active stakeholder group was therefore important. This continued discussion ensured legitimacy and credibility of the modelling output for all the active stakeholders. Over time, the active stakeholders developed their own model interpretations and suggested scenarios to be tested with the model outputs. As confidence in their modelling skills grew, and the active stakeholders increased their knowledge of the model and its limitations, and trust and interpretation of the results improved.

This transition from learners to local experts in the active stakeholders was facilitated by a structured process around the meetings (Figure 2). As highlighted in Section 2.6, the continued development of documentation and guides supported the capacity building and modelling process (https://osf.io/uqb5j/).

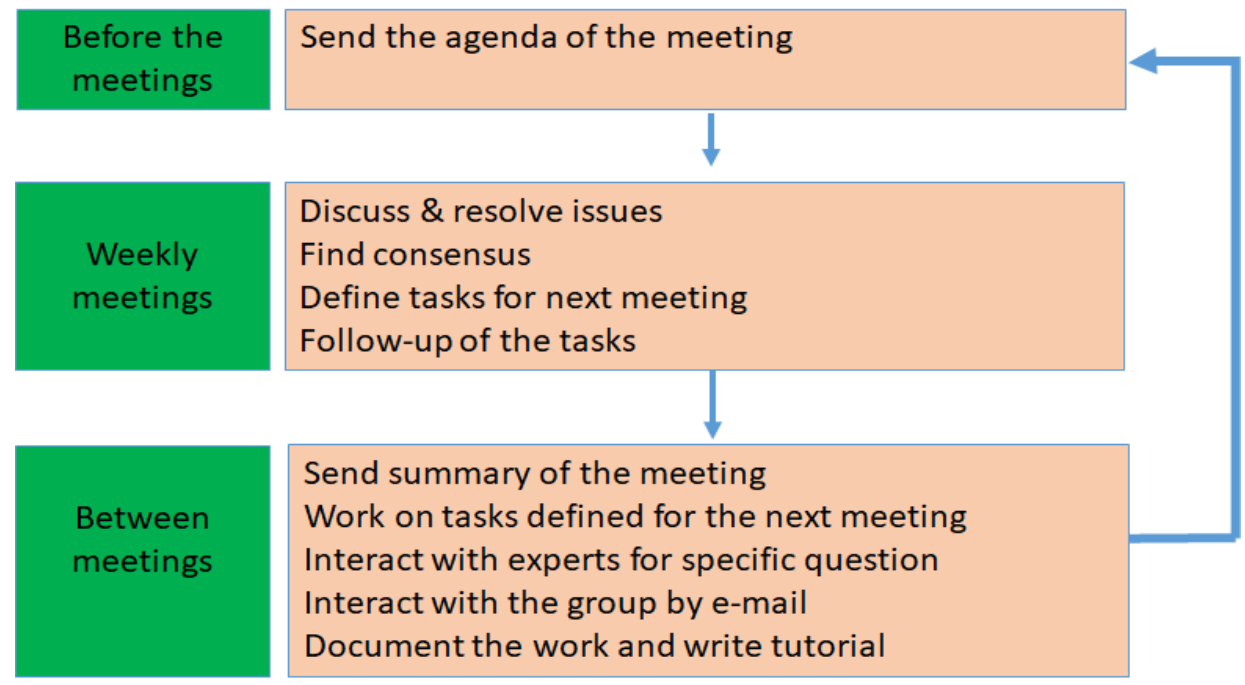

Figure 2: Schematic description of the meeting process

\section{Model implementation results}

Because a model is a simplification of reality, decisions on how to simplify processes and how they can be represented in the model have important consequences in terms of the model output (Clark et al., 2015). One challenge is at the implementation stage, where the resolution of input data and level of precision and accuracy of the input data needs to be decided among the group, and some of this discussion is highlighted below. For the active stakeholder group another challenge was that some sections of the SWAT model documentation can be somewhat cryptic and outdated. This can be exacerbated by the formal treatment in the text and sometimes differences in acronyms between the SWAT theory documentation and the model files. This created some significant start-up problems in the implementation of the model, as some of the parameters and processes were not directly clear. Furthermore, SWAT was developed in the Northern Hemisphere and many of the 
example studies are from the US. Adaptation to the specific Uruguayan case study meant that several databases needed updating (such as the specific crop and soil parameters), and active stakeholders had different opinions with respect to implementation, which is reported in more detail below.

Our role as facilitators and process coaches was to assist the active stakeholder group in making a decision, and if needed, suggest different alternative approaches that could be tested against each other.

In the following paragraphs, we describe and highlight the following discussions in the active stakeholder group:

- the watershed level implementation and subdivision in subbasins;

- the quality of the land use map, and which land use map to choose for the model setup and subsequent calibration, as this links to the time period to be simulated;

- the assumptions of stationarity of land uses in the model and in the landscape;

- the implementation of crop and agricultural management practices in the model to represent the agricultural activities in the basin as specific crop parameters; and

- the decision on whether or not to include point sources and how to implement this in the model.

We detail how the active stakeholder group reached decisions on these.

\section{Watershed level implementation}

As highlighted in the model description and basin delineation, the subbasin level and spatial resolution of the model can be challenging. During our first official group meeting (30/01/2018), the coordinator raised the possibility of working at different levels of the watershed and linking the watershed level to the existing hydrological subdivision maps available in Uruguay. Immediately, there were different answers from institutions and level interest. MVOTMA-DINAMA, IMFIA and MGAP initially preferred to work at level 3, a coarser hydrological subdivision, to be able to compare results with the AQUATool model they were using earlier. On the other hand, MVOTMA-DINAGUA and INIA prefered that the model would be developed at a finer spatial resolution, which is the smallest official basin division (level 5). After one-week reflection between two meetings, the active stakeholder group decided to implement the SWAT model at both level 3 and level 5 to be able to compare the results at a later stage. MVOTMA-DINAMA, IMFIA and MGAP worked at level 3 , while INIA and MVOTMA-DINAGUA worked at level 5. However, quite quickly in the project, the main modeller from MVOTMA-DINAGUA moved to a new position at IMFIA and was no longer able to attend the meetings. As a result DINAGUA no longer had a "modeller" as an active stakeholder and only INIA was left to implement the model at level 5 . One of the experts also built the model at level 5 to support the INIA efforts and to offer a comparison.

\section{Land use map quality}

Several land use maps were available for the study period. MVOTMA classified satellite images based on the "Land Cover Classification (LCCS)" methodology of the Global Land Cover Network (GLCN) of the United Nations' Organization for Food and Agriculture (FAO). Using this method, land use maps have been published for 2000, $2008,2012,2015$. For the model development one of the maps had to be selected. The group worked on several quality checks and discussed with the team who created the maps (some of whom are part of the active stakeholder group) to help in the decision process. After some meetings, the group decided to discard the 2008 and 2012 land use maps due to perceived lower quality. To further strengthen the credibility and legitimacy of the data, the active stakeholders members participated in a one-day field trip to the basin to qualitatively verify both land use maps. The 2000 and 2015 land use maps were both considered possible options for implementation in the model.

\section{Stationarity of land uses assumptions}

As observed land use change was more rapid after approximately 2008 (Navas et al., 2019), the majority of the group initially used the 2000 map to perform the model calibration from 2000 to 2007 based on a relatively stable (stationary) land use period. However, part of the group developed an additional model using the 2015 map, as most of the observed water quality data are available after 2011. After the first year, which focused mainly on water quantity calibration, all models were redeveloped based on the 2015 map, which allowed for joint water quantity and quality calibration. 


\section{Crop parameters and agricultural management practices implementation}

As highlighted in the methods, implementing typical crop rotations is a difficult task and took several weekly meetings to define the most representative rotations. The challenge included defining crop-pasture sequences for the model that best represent the actual (non-stationary) crop rotations in the basin. It also involved checking that the simulated biomass production of the different crops was realistic. Within the active stakeholder group, the "controllers" were involved in collecting specific data of typical crop rotations and biomass values, while the "modellers" in the team implemented the collected information in SWAT and produced simulation outputs for comparison. Advice from external experts resulted in agreement between the active stakeholders on three main rotations (Supplementary Material Table S2). To capture the ongoing learning, all the steps and decisions were recorded in the pilot project documentation.

As an example of the process, the initial uncalibrated model runs produced unrealistic biomass values. These were subsequently discussed in the group and compared to realistic values for Uruguayan farming systems. In general, biomass and yields values were overestimated, and this resulted in identifying issues with the model's radiation use efficiency parameter (BIO_E) which influences the total production of biomass per year. After conducting a literature review to find consensus within the group, the BIO_E values in the original SWAT database appeared generally overestimated for Uruguay. Subsequently, after discussion and evaluation in the group, the BIO_E values in the model plant database were adjusted to achieve reasonable biomass values. This verification process also resulted in capacity building, as it improved understanding of the parameters in the crop module and how these can be adapted to the local context from the default US conditions.

\section{Point sources implementation}

The implementation of diffuse contamination from dairy farms was a challenging discussion point. MVOTMADINAMA had collected discharge monitoring data for three domestic effluent points and two industry discharge points and these were included in the model. However, there was no data related to discharge from dairy farms, which was considered to be a possible source of nitrate and phosphorus by the active stakeholder group. After a review of relevant literature and consultation with local experts, the group agreed to include one point source per subbasin to take into consideration the diffuse contamination from dairy farms.

\section{Model outputs, credibility of the model}

The initial model calibration focused only on water quantity. The calibration and validation of the model were based on the SWAT Calibration and Uncertainty Program (SWAT-CUP). To familiarisze the group with SWATCUP, we started with monthly discharge calibration which can quickly result in good results, as this mainly matches the water balance. Subsequently, we implemented the calibration and validation of daily discharge using three stream gauge stations. This proved more challenging and resulted in several discussions related to the quality of the data at the streamflow stations and the meteorological stations. As this is a sensitive point for one of the institutions responsible for the collection of the data, this is a discussion point that continues. As an intermediate step, the model was calibrated using only two of the stations, which were considered to have the best quality data. The group also completed a formal water quality calibration using SWAT-CUP, but this is limited by the available water quality data: it is based on bimonthly sampling and it covers only a reduced number of years.

Overall, the group efforts resulted in a calibrated and validated model for the basin using different methods (Figure S2 and Table S3). While the overall results were not outstanding in terms of the existing literature in hydrological modelling (Brown et al., 2015; Molina-Navarro et al., 2017), it provided a sufficient basis for the group to continue exploring model scenarios. 


\subsection{Extending the results of the pilot group}

\section{Continued model work and scenarios}

Encouraged by the initial flow calibration results and despite considerable remaining uncertainty, the group was keen to start with water quality analyses and developing modelling for different scenarios. In particular, the group was interested in simulating nitrogen and phosphorus loads related to management of dairy effluent and looking at a buffer zone or filter strip scenario.

The importance of representative sediment and nutrient loads in the base simulation related to the discussions around scenario development. Policy and decision makers in the wider stakeholder workshops identified that a scenario that considered the impact of implementing different sizes of buffer zones in the basin to manage sediment and nutrients was important. This is because the action plan of the Santa Lucia basin calls for the implementation of buffer zones with a given dimension (Anonymous, 2018) to manage water quality. To implement this in SWAT is somewhat difficult as the conceptualisation in SWAT is different from the process envisioned in the action plan. Thus, filter strips in SWAT are conceptualised as "end of field" strips at the HRU level, while in the real basin, the filter strips are more similar to riparian zone management, which would operate at the subbasin level. We also identified weaknesses in the SWAT theory documentation in relation to the implementation of the filter strips scenario, with uncertainty around the choice of parameters; the workflow was recorded (https://osf.io/uqb5j/). In addition, a small sensitivity analysis of filter strips was performed which identified that the main sensitive variable was the field to filter strip ratio. In the scenario developed by the active stakeholder group, the ratio was based on the widths of the proposed buffer zones (Anonymous, 2018).

The model was calibrated on the available water quality data (nitrate, phosphorus), even though the observed data were very limited (Table S3 and Figure S2). This also meant that the model calibration, which initially concentrated on the period 2000 - 2007 had to shift to 2010 - 2015 as more water quality data were available in this period. A further complicating factor was that the land use within the basin between 2010 and 2015 is probably less stationary, which can influence the uncertainty of the final results. This was debated, but in the end, the need to deliver water quality predictions overrode the other concerns. The group discussed soft data approaches to verify the water quality results, such as simply investigating whether the simulated values followed the same general distribution in overall values as the observed data at a gauging location. These first analyses suggested that the model has difficulties in simulating phosphorus loads, but can simulate nitrogen loads. As a result all the processes in the model related to phosphorus loads were investigated and the associated input data checked. This led the group to investigate what would be the appropriate parameters for predicting soil erosion for Uruguay as the default parameters might again not be representative. The group is currently working through comparisons with model runs to test the impact of improved parameter estimates.

Sediment predictions from the model are also an area of interest for the group as they relate to nutrient and chemical runoff. The difficulty was that there were no observed data on sediment transport, so we relied on the results of erosion model simulations in Uruguay (García-Préchac and Durán 2001), expert opinion and the controllers in the group (i.e. soft data) to approximate realistic values for Uruguay for sediment delivery to the stream.

\section{Measuring success}

Another way to measure the success of the project is to summarise the project against 15 criteria related to credibility, salience and legitimacy and the five dimensions of participation offered by Falconi and Palmer (2017) (Tables 3 and 4). The dimensions of participation (Table 4) focus on an evaluation of the project based on who participated, what level of participation took place, how involved the stakeholders were, whether the project actually had an opportunity of exert influence and finally what the main purpose of the project was. Based on our own (biased) evaluation, our project scores relatively high in terms of success in PM (Table 3). In addition, our project has high levels of participation from all relevant stakeholders (Table 4). 
Table 3: Self-evaluation of the 15 criteria related to Credibility, Salience and Legitimacy of the project (Falconi and Palmer, 2017).

\begin{tabular}{|c|c|c|}
\hline $\begin{array}{l}\text { Criteria Description from Falconi and } \\
\text { Palmer (2017) }\end{array}$ & This project & Comment \\
\hline Credibility & & $\begin{array}{l}\text { Definition: Does the model accurately represent the system as seen } \\
\text { by the stakeholders? }\end{array}$ \\
\hline $\begin{array}{l}\text { C1 ldentifies knowledge gaps, crucial } \\
\text { issues, and discrepancies in problem } \\
\text { understanding }\end{array}$ & High & $\begin{array}{l}\text { Face-to-face meetings were used to reach agreement between } \\
\text { stakeholders on: } \\
\text { - Soil maps, land use maps, characteristics of dairies in the model } \\
\text { - Identified data gaps and data inaccuracies } \\
\text { - Approaches to conceptualising the basin } \\
\text { Agreements were documented and reviewed within the group. }\end{array}$ \\
\hline $\begin{array}{l}\text { C2 Builds shared understanding of } \\
\text { facts and language as the starting } \\
\text { point for discussions }\end{array}$ & High & $\begin{array}{l}\text { Regular face-to-face meetings and a focus on a single case study } \\
\text { results in shared understanding of facts and language. This was } \\
\text { further strengthened by the capacity building workshops. }\end{array}$ \\
\hline $\begin{array}{l}\text { C3 Uses data/information derived } \\
\text { from trusted sources }\end{array}$ & High & $\begin{array}{l}\text { See table } \mathrm{S1} \text { which highlights the use of only trusted government } \\
\text { sources of data for the project. }\end{array}$ \\
\hline $\begin{array}{l}\text { C4 Provides means for stakeholder } \\
\text { inclusion in relevant dialogues }\end{array}$ & Medium & $\begin{array}{l}\text { The active stakeholders were "appointed" by the decision maker } \\
\text { stakeholders, so we are unsure whether we have captured all the } \\
\text { different stakeholders. However, within the active stakeholder } \\
\text { group the consensus model allowed everybody to participate. }\end{array}$ \\
\hline $\begin{array}{l}\text { C5 Promotes communication, } \\
\text { enhanced credibility and } \\
\text { accountability of information, and } \\
\text { bridges gaps in new perspectives }\end{array}$ & High & $\begin{array}{l}\text { All data, decisions and information were made accessible to all } \\
\text { stakeholders via repositories. Moreover, } \\
\text { regular update meetings with the wider stakeholder group were } \\
\text { organized to discuss progress and solicit feedback. } \\
\text { We also brought in external experts to build capacity and resolve } \\
\text { discussion points. }\end{array}$ \\
\hline
\end{tabular}

\section{Salience}

Definition: Is this a problem that the stakeholders would like to see addressed? And, do the model outcomes address the needs of the stakeholders?

\begin{tabular}{lll}
\hline $\begin{array}{l}\text { S1 Builds effective and frequent } \\
\text { communication channels in a two- } \\
\text { way dialogue }\end{array}$ & High & $\begin{array}{l}\text { We had weekly face-to-face meetings where all active stakeholders } \\
\text { had an equal role. }\end{array}$ \\
\hline $\begin{array}{l}\text { S2 Translates information and } \\
\text { technology results to address end- } \\
\text { user needs }\end{array}$ & Medium & $\begin{array}{l}\text { While there is potential to translate the output from the group to } \\
\text { policy, this has not yet happened. }\end{array}$ \\
\hline $\begin{array}{l}\text { S3 Incorporates diverse knowledge } \\
\text { from a range of users }\end{array}$ & High & $\begin{array}{l}\text { The project brought together different institutions and combined } \\
\text { research organisations with government institutions. }\end{array}$ \\
\hline $\begin{array}{l}\text { S4 Results in a single-text document } \\
\text { as an agreement on a set of facts } \\
\text { and a platform for co-production }\end{array}$ & Medium & $\begin{array}{l}\text { We did not create a single document, but we have documented all } \\
\text { steps in the process and this is agreed by all group members. These } \\
\text { were presented as reports to the overall stakeholders in March } \\
\text { 2020. }\end{array}$ \\
\hline $\begin{array}{l}\text { S5 Helps link relevant questions to } \\
\text { end users to answers model can } \\
\text { accurately provide }\end{array}$ & Medium & $\begin{array}{l}\text { As this paper mainly describes a pilot project, the scenario } \\
\text { development that focuses on answering relevant questions from } \\
\text { the end users is still in progress. However, all stakeholders are } \\
\text { engaged in the process and are keen to see answers from the } \\
\text { modelling effort. }\end{array}$ \\
\hline
\end{tabular}


Table 3 (continued)

\begin{tabular}{|c|c|c|}
\hline $\begin{array}{l}\text { Criteria Description from Falconi and } \\
\text { Palmer (2017) }\end{array}$ & This project & Comment \\
\hline Legitimacy & & $\begin{array}{l}\text { Definition: Is the model seen as unbiased and does it not represent } \\
\text { a specific view point? }\end{array}$ \\
\hline $\begin{array}{l}\text { L1 Provides open and transparent } \\
\text { criteria for decisions and rules of } \\
\text { conduct }\end{array}$ & Medium & This is not formal, but implicit in the group operation. \\
\hline $\begin{array}{l}\text { L2 Allows real-time criticisms, } \\
\text { feedback, and update mechanisms }\end{array}$ & High & $\begin{array}{l}\text { Our weekly face-to-face meetings with the active stakeholder } \\
\text { group allowed extensive discussion, in which feedback from } \\
\text { external stakeholders was reviewed and results from different } \\
\text { individuals were discussed and criticised. }\end{array}$ \\
\hline $\begin{array}{l}\text { L3 Accommodates new } \\
\text { information/preferences through } \\
\text { model flexibility and acts as } \\
\text { educational tool to users }\end{array}$ & High & $\begin{array}{l}\text { Because the whole field of landscape modelling was new for the } \\
\text { active stakeholders, the model served both as a capacity building } \\
\text { tool and a means of answering questions. The model is flexible and } \\
\text { not all parts of the model need to be used which means that } \\
\text { depending on the decisions in the group different emphasis can be } \\
\text { applied. }\end{array}$ \\
\hline $\begin{array}{l}\text { L4 Analyses alternative scenarios to } \\
\text { create a collaborative environment } \\
\text { and converge on solutions }\end{array}$ & High & $\begin{array}{l}\text { Within the active stakeholder group (and as described in the model } \\
\text { implementation section) several alternative approaches were } \\
\text { tested and collaboratively evaluated during the process. This then } \\
\text { resulted in a collaborative consensus and the group moved forward } \\
\text { to the next problem. Scenarios continued being developed } \\
\text { collaboratively by the stakeholder group. }\end{array}$ \\
\hline $\begin{array}{l}\text { L5 Elucidates decision process } \\
\text { through forum, provides insights } \\
\text { rather than "optimal" solutions }\end{array}$ & Medium & $\begin{array}{l}\text { Because the model solutions are not yet fully integrated into a } \\
\text { decision process, this cannot yet be fully evaluated. However, the } \\
\text { overall collaborative process resulted in different insights into the } \\
\text { modelling process, uncertainties, data gaps and limitations. } \\
\text { Because this is all well documented, it leads to adjustment in } \\
\text { workflows and activities in the different departments. The main } \\
\text { example for this is the documentation of the land use maps and the } \\
\text { realisation by the relevant department that the actual process of } \\
\text { generating two of the land use maps was not well documented, } \\
\text { making these maps less reliable. }\end{array}$ \\
\hline
\end{tabular}

Table 4: Dimensions of participation for the project (Falconi and Palmer, 2017)

\section{Dimensions (Falconi and Palmer, 2017) This project}

Participants

Uruguayan government departments, Universities, research center as INIA, organising and experts team from IRI and USYD.

Stages of participation

Data collection, model conceptualisation, problem definition and identification, model building, calibration and use, model validation using relevant data and soft data.

Degrees of involvement

"Modellers and controllers": Collaborative modelling, but part of the group was active in the modelling process while another part of the group mainly operated as advisers. 


\section{Discussion}

This paper describes an IWRM project involving participatory modelling (PM) (Voinov and Bousquet, 2010) where part of the active stakeholder group are the actual modellers, which is relatively uncommon (Voinov et al., 2016). This organically resulted in a collaborative governance structure (Ansell and Gash, 2008) which appeared to work effectively. The consensus driven modelling approach was supported by a larger group of stakeholders and this has resulted in general acceptance of the modelling work and initial outcomes. Analysing why this case study in Uruguay has so far been successful can possibly help other projects achieve similar outcomes.

This paper inevitably had to choose between reporting on the PM and stakeholder processes, or dedicate more space to the actual model implementation. As a result we recognise that the description of the model implementation is fairly brief and does not cover detail about model results, behaviour and actual scenario implementation. We hope to cover this in more detail in a future technical paper on the modelling. Some details about model results are found in the Supplementary Material attached to this paper.

While we can now see this project within the PM framework (Voinov et al., 2016), this was not part of the original design. As a result, the original approach in the project did not follow many of the recommendations in the literature (i.e. Langsdale et al. 2013; Badham et al. 2019; Hamilton et al. 2015). For example, the process was not carefully planned (Badham et al. 2019; Hamilton et al. 2015), but the group came together in an ad-hoc manner as a result of a workshop, similar to typical groups described by Merritt et al. (2017). In addition, the group used a complex model, which can make it difficult for the stakeholders to be actively involved in the modelling (Olson and Anderson, 2007; Haasnoot et al. 2014).

However, reflecting back on the components of PM outlined in Voinov et al. (2016), we can see that we applied several of these components in our project (Table 5).

Table 5: Mapping the project activities to the PM components outlined in Voinov et al. (2016).

\begin{tabular}{ll}
\hline Voinov et al. (2016) PM components & This project (all through face-to-face meetings) \\
\hline 1) Scoping and abstraction & $\begin{array}{l}\text { The first workshop with the larger stakeholder group in July 2015, } \\
\text { followed by selection of an active stakeholder group by decision makers } \\
\text { in the overall stakeholder group. }\end{array}$ \\
\hline 2) Envisioning \& goal-setting & $\begin{array}{l}\text { Active stakeholder meetings leading to the pilot project proposal and } \\
\text { establishment, including model selection. }\end{array}$ \\
\hline $\begin{array}{l}\text { 3) Model formulation, 4) collection of original } \\
\text { data, and 6a) Evaluation of outputs }\end{array}$ & $\begin{array}{l}\text { The active stakeholder group meetings and the modelling as part of } \\
\text { these meetings by the "modellers". Active continuous evaluation of the } \\
\text { data and modelling by the "controllers" (or gatekeepers), with support } \\
\text { from the experts, who also acted as facilitator and process coaches. }\end{array}$ \\
\hline $\begin{array}{l}\text { 6b) Evaluation of outcomes, and 7) facilitation } \\
\text { of transparency of the process }\end{array}$ & $\begin{array}{l}\text { Larger stakeholder meetings such as in February 2019 and June 2019. } \\
\text { These meetings were led by the active stakeholders (as indicated by } \\
\text { Voinov et al., 2016) and the facilitator and process coaches input was } \\
\text { limited to organisation and feedback. }\end{array}$ \\
\hline 7) Facilitation of transparency of the process & $\begin{array}{l}\text { Publication of the methods and some of the outcomes on the Open } \\
\text { Science Framework (OSF) site }\end{array}$ \\
\hline
\end{tabular}

In the PM process in this project, the approach concentrated on typical face-to-face workshops. This was partly because the active stakeholder group was relatively small and larger meetings with the overall stakeholder group were limited to a few over the period of the project. One activity this project has yet to cover is applying the model to decision making (the $5^{\text {th }}$ PM component in Voinov et al., 2016), as scenario runs are still being planned and developed. Another interesting point to note is that Voinov et al. (2016) highlight "Stakeholder involvement is relatively rare here" (p. 199) with the $3^{\text {rd }}$ PM component (Model formulation). In this case study, 
this was the most important stakeholder involvement with the active stakeholder group. Another element that does not seem to be part of the PM framework as outlined in Voinov et al. (2016) is the need for capacity building in the stakeholder group. In this case study, this was very explicit, because without training in the use of the model, the project could not proceed. However, we would envision that in all PM projects there is a need for some capacity building to enable stakeholders to familiarise themselves with the modelling, the data and the application of the model to scenarios.

The collaboration that happened without any structural approach can be partly captured in our interpretation of the 'model of collaborative governance' in Ansell and Gash (2008) (Figure 3 below).

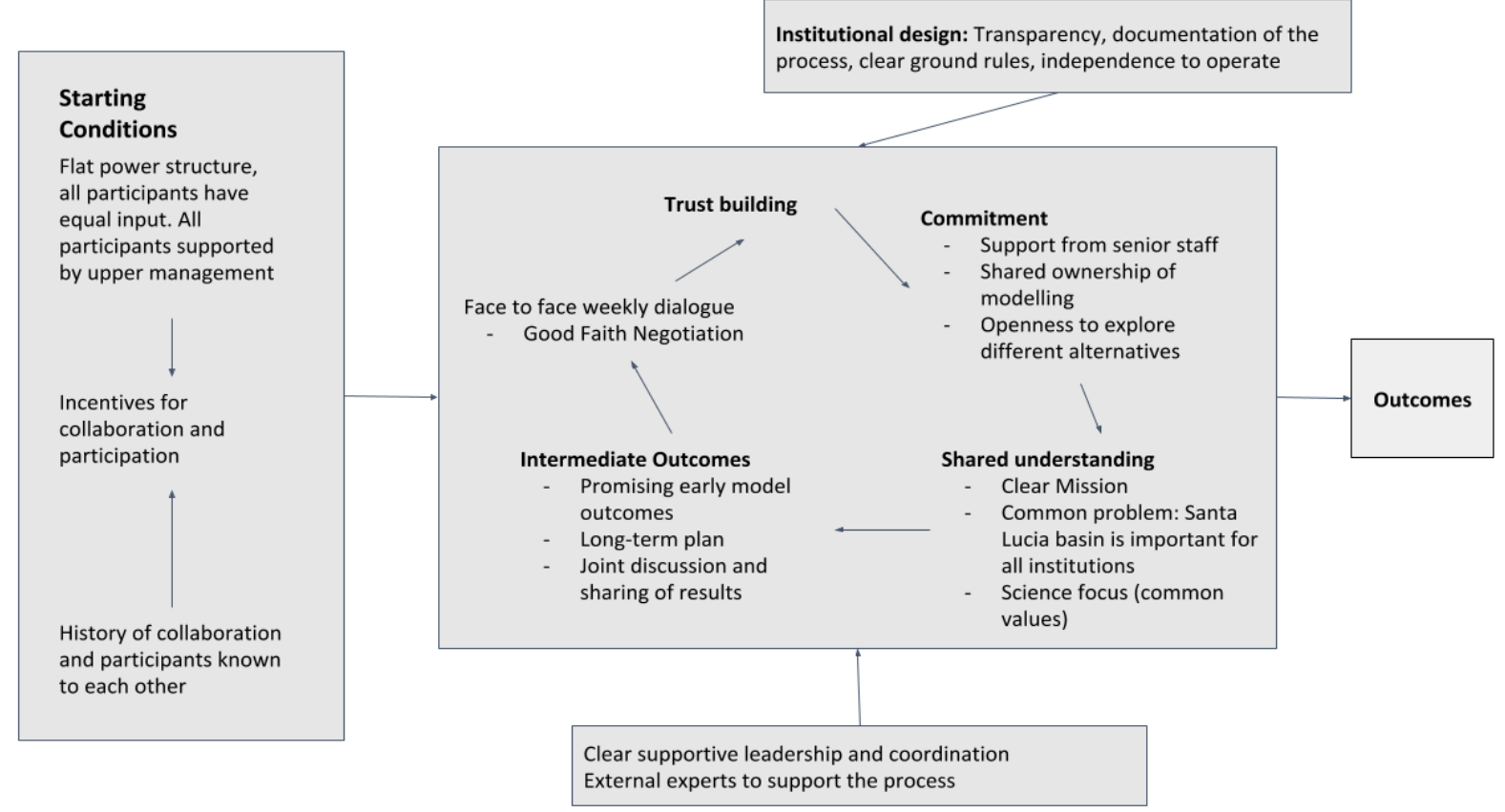

Figure 3: After Ansell \& Gash (2008): Success factors in the participatory modelling group for the Santa Lucia project, interpreted as collaborative governance.

The active stakeholder group started with favourable initial conditions: a flat power structure, initial existing trust between the participants and strong incentives for participation, and importantly, the support from the upper echelons (Figure 3). This support was a result of the initial IRI strategy workshop that built consensus between department heads. In addition, there was a strong joint focus on the scientific aspects in the project. While the chosen model, SWAT, is complex, it was supported by capacity building through the strong involvement of external expertise. This resulted in continual learning (Bodin, 2017) which is important for motivation. The fact that we could quite rapidly deliver initial results, clearly increased the motivation of participants to continue with the modelling (e.g. Langsdale et al. 2013). This also encouraged more of the participants to become active in the actual modelling activities. A further advantage of the continued learning is that the increase in understanding of the modelling within the group allows quite rapid changes in the modelling process (such as changes regarding the model hypotheses, model parameters and delivery of different model results).

The weekly meetings offered an opportunity for face-to-face interaction, which supports openness and good faith negotiation (Falconi and Palmer, 2017; Merritt et al., 2017). This is partly a result of the institutional design of the project under the wider INIA-IRI-USYD project and as such offers a neutral space for the discussions. However, this meant the role of the coordinator/facilitator was essential to keep the process on track, maintain the project structure, and maintain contact with the wider network (Bodin, 2017). The academic and scientific leadership was strengthened by the inclusion of external experts in the project (Figure 1) and through the input from the controllers in the group. This allowed the project to pull in local scientific knowledge (Merritt et al., 2017) thus strengthening the representation of the basin in the modelling. The role of the controllers brought additional depth to the weekly meetings. While the controllers might find it difficult to work in the actual 
modelling, the group process meant that their input was valued and they felt valued as active stakeholders, resulting in shared ownership of the modelling (Figure 1).

We found that the role of an energetic and positive coordinator for the diverse project group, whose members have other demands on their time, is very important. This reflects the role of facilitator highlighted in many of the PM literature (Ansell and Gash, 2007; Voinov and Bousquet, 2010). The overall positive atmosphere created in the group helped to overcome several difficult topics. Indeed, it has been shown that positivity enables more diverse thinking, acceptance of alternatives, and in collaborative meetings leads to easier consensus (Ansell and Gash, 2007; Hämäläinen, 2015).

The other important role of the coordinator was in recording the results and managing the documentation (Merritt et al., 2017), which again was also an important part of the capacity building and collaborative learning (Bodin, 2017; Fu et al., 2019). This was particularly important as all participants (both active and other stakeholders) needed to be engaged and informed. Even detailed documentation of the deliberations at each meeting did not prevent repetition of discussions because participants had not read the past notes. We extensively used digital platforms such as Google drive, on-line meetings and a Whatsapp group (as suggested in Voinov et al. 2016), but this still required stakeholders to spend time reading and digesting information that had been provided. It has been suggested that using digital platforms can lead to less frequent and shorter meetings, "because all the information is in the <shared resource>". However, in practice, this requires stakeholders to prepare in their own time. In our case the active stakeholders were more interested in actually resolving issues and doing work in the allotted meeting time as this was time assigned to them by their superiors. However, as time went by, we qualitatively observed an increase in activity outside the meeting time and an increase in communication via digital media. Voinov et al. (2016) discusses that this can lead to "asynchronous" conversations, in relation to being part of live discussions or via digital platforms, but in this case it was also related to stakeholders not keeping up with the digital conversations.

As we highlighted in the results, starting with a novice group using a complex open source model such as SWAT can be difficult. Some of the difficulties encountered are not really solvable and simply relate to the complexity of the model. As a project, we might have even added to the confusion by creating further, well meant, capacity building material on the OSF platform (https://osf.io/uqb5j/). For example, we added additional information and interpretations of the manuals about the specific crops, vegetation parameters including documenting decisions on soil data and explanations of some of the theory documentation and steps. This might have suited our specific project, but might not be generally applicable. However, it should be of use to further applications of SWAT in Latin America.

There is probably no easy solution to the clutter of information, which is the result of the more general, open source, internet age problem. One possible option is a more coordinated approach from the SWAT global modelling community, including additional "gatekeepers" that organise and review material. This happens in large mature open source communities, for example the R community (https://www.r-project.org/). However at this point, the SWAT global community has not yet reached that level of organisation. One possible reason for this is that there is a very large global community of SWAT users, but a very small SWAT developer community (https://swat.tamu.edu/). This small group of people try to develop new model code, create documentation, give support and provide a consistent message (single source of truth) to all the global users who are mostly interested in simply applying the model. More active development of organised "nodes" of the user community in different continents, and in this case in Latin-America, with gatekeepers and managers would improve this. However, this requires investment of resources, which might not necessarily be available. An organisation, such as INIA Uruguay, or one of its Latin-American sister organisations, would be the natural host for a node.

Another issue was to identify and manage possible biases in the process (Hämäläinen, 2015). Firstly there could be a risk of loss aversion, given that we used a complex model, in which the participants have invested significant time and effort. We might be sticking with the model longer than needed if at some point we recognised that the model is not suitable for the project. There was also some risk for confirmation bias and group-think. We had a fairly unique stakeholder group. This was a group of scientists who have an interest in modelling and the success of this project. It is possible that we therefore agreed more easily about the results rather than thinking "outside the box" to identify other options. There were however some factors that counteract this within the project. While there is strong emphasis in the literature on the selection of stakeholders (Hamilton et al., 2015; Langsdale et al., 2013), in our case it resulted from a more natural process. As a result, the group consisted of 
stakeholders with competing visions of the future of the basin, which is further supported by the wider stakeholder group including the superiors of the group members. This means that a variety of opinions existed within the group, leading to diverse discussions (Falconi and Palmer, 2017). Furthermore, the input of the IRIINIA-USYD "facilitator and process coaches" helped the group challenge their own thinking and be critical about the results. There could be some danger of authority bias in this (Hämäläinen, 2015), but as the capacity within the group grew, this encouraged further critical analysis of the results and assumptions.

The size and membership of the active stakeholder group was one of the more difficult components to manage. While smaller groups are easier to manage, our initial success has now led to more people wanting to join the group. This is particularly because the group offered the opportunity to learn about modelling as part of the capacity building effort. Larger groups, from a diversity and capacity building point of view, can offer advantages as this is less likely to result in some of the identified biases (Hämäläinen, 2015). However, larger groups might struggle with trust and good relationships, as well as stakeholder buy-in and ownership (Merritt et al., 2017).

In this project, the stakeholders were directly involved in the construction and development of the models (Basco-Carrera et al., 2017). This enabled the research institutions (INIA and IMFIA, Table 1) to work closely with the governmental agencies. Generally public institutions prefer to use up-to-date science to implement good policies. However, sometimes the "virtual" distance between government and research can be quite large. Working together allows direct communication, building of trust and ensures that the research addresses the needs of the policy makers.

The pilot project finished in March 2020. Looking towards the future with the success of the initial pilot project, the departments have encouraged the active stakeholder group members to continue working with SWAT, but extending to projects in different basins. This has resulted in new members joining the PM group. For the group activities, this means that it will transition from a specific project PM group with direct stakeholders to a "virtual SWAT modelling work space". Here, people working on different modelling projects will collaborate to improve modelling skills and to evaluate results using the access to experts to act as controllers.

\section{Conclusions}

Overall, the project provides a case study of participatory modelling (PM) with stakeholders to deliver integrated water management. This provides several insights that might assist future projects in this area. In the end, an ad-hoc organisation of the PM process did not seem to limit the effectiveness of the stakeholder interaction, but looking back, we basically followed most of the steps outlined by Voinov et al. (2016). We found that the Falconi and Palmer (2017) framework capturing the concepts of salience, legitimacy and credibility as applied to PM processes was useful to analyse the development and success of the PM project, in addition to the concept of collaborative governance from Ansell and Gash (2007).

In this study the stakeholders identified a complex model (SWAT) as the model of choice. Using a complex model for PM with a "novice" group of modellers required significant investment in capacity building: in this case three short courses and continued coaching from the expert team from IRI and USYD. In addition, a dedicated person attached to the active stakeholder group to keep the project focused and manage the information flow was important.

In the end, the focus on a single salient basin, the willingness to learn, the support from the leadership in the different institutions for the active stakeholders, and the multi-institutional interaction between the active stakeholders increased the commitment of the people involved and made the project relevant for the wider group of stakeholders. This contributed strongly to the success of the project. However, we identified, from a model implementation perspective, that there is a clear need for a more organised approach to the vast amount of open source documentation and information that is generated as part of the online SWAT user community. The documentation that we made available at the OSF site (https://osf.io/uqb5j/) can contribute to the development of the Latin American and global SWAT model community. 


\section{Acknowledgements}

This project was funded through INIA Uruguay under FPTA 341 "IRI Contribution to climate risk management in the agricultural sector of the Southern Cone". The authors would also like to recognise the participants in the SWAT pilot project: Pablo Kok, Pablo Pereyra, Luciana Badano, Natalia Neighbur, Alberto Baccino, Fernando Diaz, Florencia Hastings, Bettina Miguez, Jimena Alonso, Angela Gorgoglione, Rafael Navas, Guadalupe Tiscornia and many others in Uruguay who contributed to the project.

\section{References}

Abbaspour, K.C., Rouholahnejada, E., Vaghefia, S., Srinivasan, R., Yang, H., \& Kløved, B. (2015). A continental-scale hydrology and water quality model for Europe: Calibration and uncertainty of a high-resolution large-scale SWAT model. Journal of Hydrology, 524, 733-752. https://doi.org/10.1016/j.jhydrol.2015.03.027

Achkar, M., Dominguez, A., \& Pesce, F. (2012). Cuenca del Río Santa Lucía-Uruguay Aportes para la discusión ciudadana. Fac. Cienc.-UdelaR REDES- Programa Urug. Sustentable. https://www.redes.org.uy/wpcontent/uploads/2012/12/Publicacion-Santa-Lucia-WEB.pdf

Anonymous (2018). Plan de acción para la protección de la calidad ambiental de la cuenca del río Santa Lucía. Medidas de segunda generación. https://www.gub.uy/ministerio-ambiente/sites/ministerioambiente/files/documentos/publicaciones/PLAN_DE_ACCION_RIO_SANTA_LUCIA__MEDIDAS_DE_2da_GENERACION.pdf

Ansell, $\bar{C} .$, \& Gash, A. (2007). Collaborative Governance in Theory and Practice. J. Public Adm. Res. Theory, 18, $543-571$. https://doi.org/10.1093/jopart/mum032

Arnold, J.G., Moriasi, D.N., Gassman, P.W., Abbaspour, K.C., White, M.J., Srinivasan, R., Santhi, C., Harmel, R., Van Griensven, A., Van Liew, M.W., Kannan, N., \& Jha, M. (2012). SWAT: Model use, calibration, and validation. Trans. ASABE, 55, 1491-1508.

Badham, J., Elsawah, S., Guillaume, J.H.A., Hamilton, S.H., Hunt, R.J., Jakeman, A.J., Pierce, S.A., Snow, V.O., Babbar-Sebens, M., Fu, B., Gober, P., Hill, M.C., Iwanaga, T., Loucks, D.P., Merritt, W.S., Peckham, S.D., Richmond, A.K., Zare, F., Ames, D., \& Bammer, G. (2019). Effective modeling for Integrated Water Resource Management: A guide to contextual practices by phases and steps and future opportunities. Environ. Model. Softw., 116, 40-56. https://doi.org/10.1016/j.envsoft.2019.02.013

Barreto, P., Dogliotti, S., \& Perdomo, C. (2017). Surface water quality of intensive farming areas within the santa lucia river basin of uruguay. Air Soil Water Res., 10, 1178622117715446. https://doi.org/10.1177/1178622117715446

Basco-Carrera, L., Warren, A., van Beek, E., Jonoski, A., \& Giardino, A. (2017). Collaborative modelling or participatory modelling? A framework for water resources management. Environ. Model. Softw., 91, 95-110. https://doi.org/10.1016/j.envsoft.2017.01.014

Bodin, Ö. (2017). Collaborative environmental governance: Achieving collective action in social-ecological systems. Science, 357, eaan1114. https://doi.org/10.1126/science.aan1114

Brown, S.C., Versace, V.L., Lester, R.E. \& Walter, M.T. (2015). Assessing the impact of drought and forestry on streamflows in south-eastern Australia using a physically based hydrological model. Environ. Earth Sci., 74, 6047-6063. https://doi.org/10.1007/s12665-015-4628-8

Cash, D.W., Clark, W.C., Alcock, F., Dickson, N.M., Eckley, N., Guston, D.H., Jäger, J. \& Mitchell, R.B. (2003). Knowledge systems for sustainable development. Proc. Natl. Acad. Sci., 100, 8086-8091. https://doi.org/10.1073/pnas.1231332100

Clark, M.P., Nijssen, B., Lundquist, J.D., Kavetski, D., Rupp, D.E., Woods, R.A., Freer, J.E., Gutmann, E.D., Wood, A.W., Brekke, L.D., Arnold, J.R., Gochis, D.J., \& Rasmussen, R.M. (2015). A Unified Approach for Process-Based Hydrologic Modeling: 1. Modeling Concept. Water Resour. Res. 51, 2498-2514. https://doi.org/10.1002/2015WR017198

Cosgrove, W.J., \& Loucks, D.P. (2015). Water management: Current and future challenges and research directions: Water management research challenges. Water Resour. Res., 51, 4823-4839. https://doi.org/10.1002/2014WR016869

de Fraiture, C., \& Wichelns, D. (2010). Satisfying future water demands for agriculture. Agric. Water Manag., 97, 502-511. https://doi.org/10.1016/j.agwat.2009.08.008

Falconi, S.M., \& Palmer, R.N. (2017). An interdisciplinary framework for participatory modeling design and evaluation-What makes models effective participatory decision tools? Water Resour. Res., 53, 1625-1645. https://doi.org/10.1002/2016WR019373

Fu, B., Merritt, W.S., Croke, B.F.W., Weber, T.R. \& Jakeman, A.J. (2019). A review of catchment-scale water quality and erosion models and a synthesis of future prospects. Environ. Model. Softw., 114, 75-97. https://doi.org/10.1016/j.envsoft.2018.12.008

García-Préchac, F., \& Durán, A. (2001). Estimating soil productivity loss due to erosion in Uruguay in terms of beef and wool production on natural pastures. In: Sustaining the Global Farm. Purdue University and USDA-ARS National Soil Erosion Research Laboratory, pp. 40-45. 
Haasnoot, M., van Deursen, W.P.A., Guillaume, J.H.A., Kwakkel, J.H., van Beek, E., \& Middelkoop, H. (2014). Fit for purpose? Building and evaluating a fast, integrated model for exploring water policy pathways. Environ. Model. Softw., 60, 99120. https://doi.org/10.1016/j.envsoft.2014.05.020

Hämäläinen, R.P. (2015). Behavioural issues in environmental modelling - The missing perspective. Environ. Model. Softw., 73, 244-253. https://doi.org/10.1016/j.envsoft.2015.08.019

Hamilton, S.H., ElSawah, S., Guillaume, J.H.A., Jakeman, A.J., \& Pierce, S.A. (2015). Integrated assessment and modelling: Overview and synthesis of salient dimensions. Environ. Model. Softw., 64, 215-229. https://doi.org/10.1016/j.envsoft.2014.12.005

Langsdale, S., Beall, A., Bourget, E., Hagen, E., Kudlas, S., Palmer, R., Tate, D., \& Werick, W. (2013). Collaborative Modeling for Decision Support in Water Resources: Principles and Best Practices. J. Am. Water Resour. Assoc., 49, 629-638. https://doi.org/10.1111/jawr.12065

Merritt, W.S., Fu, B., Ticehurst, J.L., El Sawah, S., Vigiak, O., Roberts, A.M., Dyer, F., Pollino, C.A., Guillaume, J.H.A., Croke, B.F.W., \& Jakeman, A.J. (2017). Realizing modelling outcomes: A synthesis of success factors and their use in a retrospective analysis of 15 Australian water resource projects. Environ. Model. Softw., 94, 63-72. https://doi.org/10.1016/j.envsoft.2017.03.021

Molden, D. (2013). Water for food water for life: A comprehensive assessment of water management in agriculture. Routledge, London.

Molina-Navarro, E., Andersen, H.E., Nielsen, A., Thodsen, H., \& Trolle, D. (2017). The impact of the objective function in multisite and multi-variable calibration of the SWAT model. Environ. Model. Softw., 93, 255-267. https://doi.org/10.1016/j.envsoft.2017.03.018

Navas, R., Alonso, J., Gorgoglione, A., \& Vervoort, R.W. (2019). Identifying climate and human impact trends in streamflow: A case study in uruguay. Water, 11(7), 1433. https://doi.org/10.3390/w11071433

Oficina de Estadísticas Agropecuarias (DIEA) (2017). Anuario Estadístico Agropecuario.Vigésima Edición. https://www.gub.uy/ministerio-ganaderia-agricultura-pesca/sites/ministerio-ganaderia-agriculturapesca/files/documentos/publicaciones/diea-anuario2017web01a.pdf

Olsson, J.A., \& Andersson, L. (2007). Possibilities and problems with the use of models as a communication tool in water resource management Water. Resour. Manage., 21, 97-110. https://doi.org/ 10.1007/s11269-006-9043-1

Oreskes, N., Shrader-Frechette, K., \& Belitz, K. (1994). Verification, validation, and confirmation of numerical models in the earth sciences. Science, 263, 641-646. https://doi.org/10.1126/science.263.5147.641

Prell, C., Hubacek, K., Reed, M., Quinn, C., Jin, N., Holden, J., Burt, T., Kirby, M., \& Sendzimir, J. (2007). If you have a hammer everything looks like a nail: traditional versus participatory model building. Interdiscip. Sci. Rev., 32, $263-282$. https://doi.org/10.1179/030801807X211720

Renger, M., Kolfschoten, G.L., \& De Vreede, G.-J. (2008). Challenges in collaborative modelling: a literature review and research agenda. Int. J. Simul. Process Model., 4, 248-263.

Voinov, A., \& Bousquet, F. (2010). Modelling with stakeholders. Environ. Model. Softw., 25, $1268-1281$. https://doi.org/10.1016/j.envsoft.2010.03.007

Voinov, A., Kolagani, N., McCall, M.K., Glynn, P.D., Kragt, M.E., Ostermann, F.O., Pierce, S.A., \& Ramu, P. (2016). Modelling with stakeholders - Next generation. Environ. Model. Softw., 77, $196-220$. https://doi.org/10.1016/j.envsoft.2015.11.016 